\title{
Prevalence of Carbapenem Resistance in Nonfermenting Gram Negative Bacteria in Patients with Respiratory Tract Infection Admitted in Intensive Care Units in Tertiary Care Centre
}

\author{
Seematai Prakash Katole and Nilekar Sandeep Laxmikant*
}

Department of Microbiology, Swami Ramanand Tirth Rural Govt. medical college and hospital, Ambajogai, Di.Beed, 431517, India

*Corresponding author

\section{A B S T R A C T}

\section{Keywords}

nonfermenting gram negative bacilli; carbapenem; Pseudomonas aeruginosa, Acinetobacter baumannii;

\section{Article Info}

Accepted: 08 January 2020 Available Online: 10 February 2020
Most common bacterial agents of Lower Respiratory Tract Infection in the Intensive Care Units are Pseudomonas, Acinetobacter, Klebsiella, Citrobacter; which are multi drug resistant, and with limiting the therapeutic options.Nonfermenting Gram-negative bacilli are known to produce Extended spectrum $\beta$-lactamases (ESBLs) and metallo $\beta$-lactamases. Pseudomonas aeruginosa and Acinetobacter spp. in particular are most often associated with carbapenem resistance. The antimicrobial susceptibility testing of non-fermenting gram negative isolates was done by Kirby Bauer disc diffusion method according to CLSI 2019 (Clinical Laboratory Standards Institute) guidelines. Out of total 227 gram negative isolates, nonfermenting gram negative bacteria were 118 . out of 118,76 were Pseudomonas aeruginosa and 42 were Acinetobacter baumannii. Out of total 76 isolated Pseudomonas aeruginosa, 33(43.42\%) were resistant to imipenem and 22(28.94\%) were resistant to meropenem. Out of total 42 isolated Acinetobacter baumannii,16(38.10\%) were resistant to imipenem and $11(26.19 \%)$ were resistant to meropenem. In view of carbapenem resistance amongst the isolates, antibiotic therapy should be advocated or modified following culture and sensitivity. This would not only help in the proper treatment of the patient but also would discourage the indiscriminate use of available antibiotics and stop the spread of drug resistance bacteria.

\section{Introduction}

Non-Fermenting Gram Negative Bacteria (NFGNB) are aerobic, non-lactose fermenting, catalase-positive coccobacilli which are developing as a major threat to critically ill patients (Agarwal S. et al., 2017). Most common bacterial agents of Lower Respiratory Tract Infection in the Intensive
Care Units (ICUs) are Pseudomonas, Acinetobacter, Klebsiella, Citrobacter (Mukhopadhyay C et al., 2003; Gonugur U. et al., 2004).which are multi drug resistant, and with limiting the therapeutic options (Goossens H. et al., 2003). Carbapenems which were introduced first in 1980 are now frequently used as the last choice in treating serious infections caused by multidrug 
resistant, gram negative bacilli which are stable to $\beta$-lactamases including the Extended Spectrum $\beta$-Lactamases (ESBLS) and Ampc (Brahmadathan K. et al., 2005;Quinn J.P. et al., 1998).

Nonfermenting Gram-negative bacilli are known to produce ESBLs and metallo $\beta$ lactamases(Gales A.C. et al., 2001). Unfortunately, resistance to these antibiotics started emerging from 1990 and has been reported in nonfermenting gram negative bacilli (NFGNB) worldwide over the years with varying frequencies (Tognim M.C.B. et al., 2004). Pseudomonas aeruginosa and Acinetobacter spp. in particular are most often associated with carbapenem resistance.

The combination of porin loss and class c $\beta$ lactamase expression is an important cause of imipenem resistance in Pseudomonas aeruginosa (Livermore DM. et al., 1992). and Acinetobacter baumannii (Devi P. et al., 2015). Here, we document the microbiological aspects of the prevalence of carbapenem resistance in NFGNB isolated from patients with respiratory tract infections in the ICU.

\section{Materials and Methods}

A total of 430 samples were processed from patients of all age groups with clinical evidence of lower respiratory tract infection admitted to medical, surgical, and paediatric ICUS from October 2017 to September 2019.

Samples were collected before starting antibiotics in sterile, wide mouthed, disposable, screw-capped container of about $100 \mathrm{ml}$ capacity (J.G. Collee et al., 1996, p63). Sample is collected before starting antibiotics (J.G. Collee et al., 1996 p63).Samples collected were Endotracheal aspirates from suction tips of patients on ventilators (Devi P. et al., 2015). Specimens ware delivered and processed within 2 hours (J.G. Collee et al., 1996, p63).

Homogenization of sputum done with dithiothreitol followed by gram staining (Duguid J.P. et al., 1996). If more than 10 polymorph per square, then Processed further. All sample were inoculated on blood agar, MacConkey agar, chocolate agar and fildes digest agar overnight at $37^{\circ} \mathrm{c}$.

Sputum samples were processed in semiquantitative method (J.G. Collee et al., 1996, p64-66). Bacterial isolates were identified according standard procedure using gram stain (Duguid J.P. et al., 1996) and using various biochemical tests (J.G. Collee et al., 1996, p131-149).

The antimicrobial susceptibility testing of non-fermenting gram negative isolates was done by Kirby Bauer disc diffusion method according to CLSI 2019 (Clinical Laboratory Standards Institute) guidelines (CLSI guidelines 2019).

\section{Statistical analysis}

The data were recorded in the MS excel and analysed by using software -SPSS version 20 .

\section{Results and Discussion}

Out of 430 samples processed,306 (71.16\%) were positive for pathogenic isolates, 73 $(16.97 \%)$ were showing normal flora growth and 51(11.87\%) were showing no growth.

Among 430 sample processed, maximum samples were from age group 51-60 i.e. 106 $(24.66 \%)$ as depicted in table 1 . Out of total 306 positive sample for pathogenic isolates, 227 (74.18\%) were positive for gram negative isolates and $79(25.82 \%)$ were positive for gram positive isolates. 
Table.1 Age wise distribution of total samples

\begin{tabular}{|l|c|c|}
\hline Age & $\begin{array}{c}\text { Number of } \\
\text { samples }\end{array}$ & Percentage \\
\hline $\mathbf{0 - 1 0}$ & 14 & $3.25 \%$ \\
\hline $\begin{array}{l}\mathbf{1 1 -} \\
\mathbf{2 0}\end{array}$ & 49 & $11.40 \%$ \\
\hline $\mathbf{2 1 -}$ & 30 & $6.97 \%$ \\
\hline $\mathbf{3 0}$ & & $8.37 \%$ \\
\hline $\begin{array}{l}\mathbf{3 1 -} \\
\mathbf{4 0}\end{array}$ & 36 & $19.55 \%$ \\
\hline $\begin{array}{l}\mathbf{4 1 -} \\
\mathbf{5 0}\end{array}$ & 84 & $24.66 \%$ \\
\hline $\begin{array}{l}\mathbf{5 1 -} \\
\mathbf{6 0}\end{array}$ & 106 & $18.37 \%$ \\
\hline $\mathbf{6 1 -}$ & & \\
\hline $\mathbf{7 0}$ & 79 & $5.34 \%$ \\
\hline $\begin{array}{l}\mathbf{7 1 -} \\
\mathbf{8 0}\end{array}$ & 23 & $2.09 \%$ \\
\hline $\begin{array}{l}\mathbf{8 1}- \\
\mathbf{9 0}\end{array}$ & 09 & $100 \%$ \\
\hline total & 430 & \\
\hline
\end{tabular}

100
-0
80
70
60
50
40
30
20
10
0

Figure.1 Prevalence of NFGNB and other isolates in the total No. of positive samples

Among total 306(71.16\%) isolated pathogenic bacteria, most common Gram-negative bacteria was klebsiella pneumoniae i.e. 93 $(30.39 \%)$ followed by Pseudomonas aeruginosa 76(24.83\%) followed by Acinetobacter baumannii 42(13.73\%) followed by Citrobacter freundii 14(4.58\%) followed by Escherichia coli 2(0.65\%). Out of total 227-gram negative isolates, nonfermenting gram negative bacteria were 118.out of 118,76 were Pseudomonas aeruginosa and 42 were Acinetobacter baumanniias depicted in table 2 and figure 1. 
Table.2 Prevalence of NFGNB and other isolates in the total No. of positive samples

\begin{tabular}{|c|c|}
\hline \multicolumn{2}{|c|}{ Total positive isolates for pathogenic bacteria (306) } \\
\hline Total gram-negative isolates $227(\mathbf{7 4 . 1 8 \%})$ & Total gram-positive isolates $79(25.82 \%)$ \\
\hline Klebsiella pneumoniae 93 (30.39\%) & Streptococcus pneumoniae 54 (17.65\%) \\
\hline Pseudomonas aeruginosa $76(24.83 \%)$ & Staphylococcus aureus 17 (5.56\%) \\
\hline Acinetobacter baumannii 42 (13.73\%) & $\begin{array}{l}\text { Coagulase negative staphylococcus } \\
\text { (CONS) } 8(2.61 \%)\end{array}$ \\
\hline Citrobacter freundii $14(4.58 \%)$ & \\
\hline Escherichia coli $2(0.65 \%)$ & \\
\hline
\end{tabular}

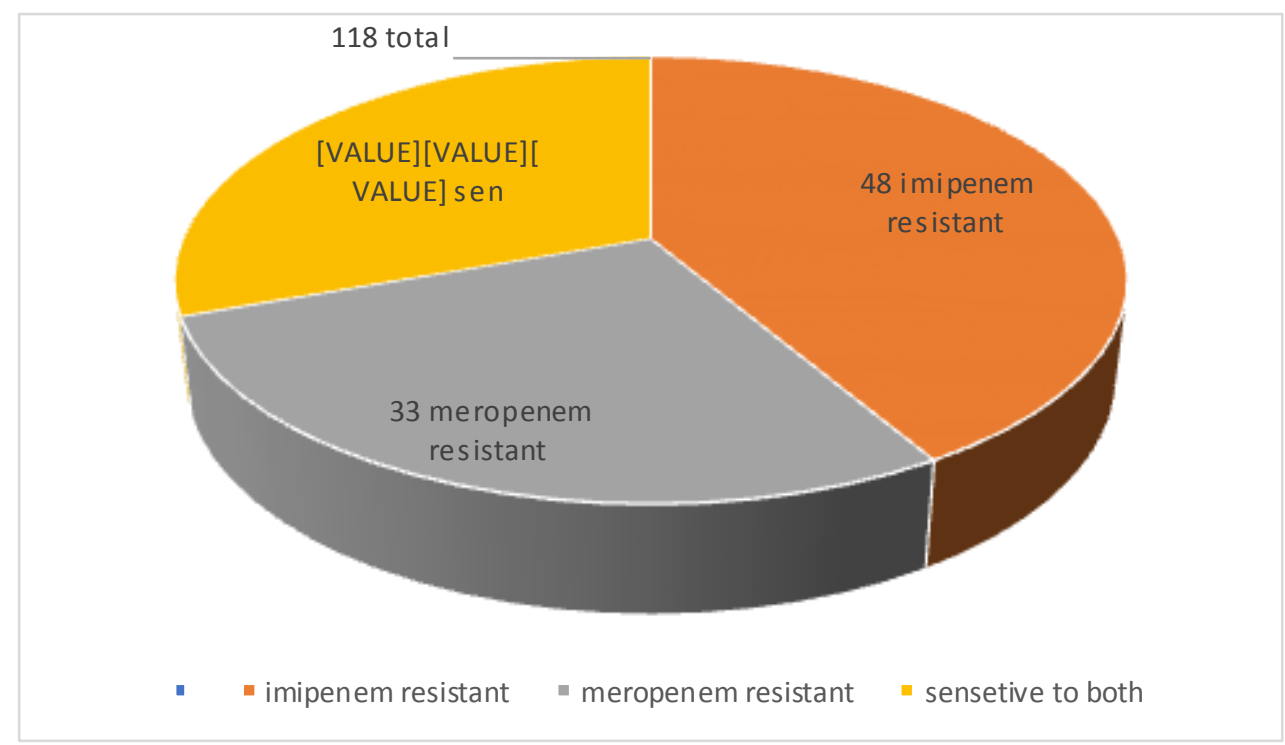

Figure. 2 carbapenem resistance in nonfermenting gram negative bacilli. $(n=118)$

Out of total 430 samples, 179 were sputum and 251 were endotracheal aspirates. Out of 306 samples positive for pathogenic bacteria, $124(40.52 \%)$ were sputum and182(59.48\%) were endotracheal aspirates.

Out of 124 positive sputum samples,31(25\%) were Pseudomonas aeruginosa and 15(12.09\%) were Acinetobacter baumannii. Out of 182 positive endotracheal aspirate samples, 45(24.72\%) were Pseudomonas aeruginosa and 27(14.83\%) Acinetobacter baumannii as depicted in table 3 . Out of total 76 isolated Pseudomonas aeruginosa,
$33(43.42 \%)$ were resistant to imipenem and $22(28.94 \%)$ were resistant to meropenem as shown in table 4.

Out of total 42 isolated Acinetobacter baumannii, 16(38.10\%) were resistant to imipenem and $11(26.19 \%)$ were resistant to meropenem as shown in table 5.

Out of 118 isolates of nonfermenting gram negative bacteria 49(41.52\%) were resistance to imipenem and $33(27.96 \%)$ were resistance to meropenem as depicted in table 6 and figure 2 .

Table.3 Prevalence of total isolates NFGNB in different samples. 


\begin{tabular}{|l|l|l|l|}
\hline Samples & $\begin{array}{l}\text { Positive samples } \\
\text { for pathogenic } \\
\text { isolates }\end{array}$ & $\begin{array}{l}\text { Pseudomonas } \\
\text { aeruginosa }\end{array}$ & $\begin{array}{l}\text { Acinetobacter } \\
\text { baumannii }\end{array}$ \\
\hline Sputum (179) & $124(40.52 \%)$ & $31(25 \%)$ & $15(12.09 \%)$ \\
\hline $\begin{array}{l}\text { Endotracheal } \\
\text { aspirates (251) }\end{array}$ & $182(59.48 \%)$ & $45(24.72 \%)$ & $27(14.83 \%)$ \\
\hline Total (430) & $306(60.51 \%)$ & 76 & 42 \\
\hline
\end{tabular}

Table.4 antibiotic susceptibility testing of Pseudomonas aeruginosa $(\mathrm{n}=76)$

\begin{tabular}{|l|l|l|}
\hline Antibiotics & Resistance & percentage \\
\hline ceftazidime & 70 & $92.10 \%$ \\
\hline cefepime & 34 & $44.73 \%$ \\
\hline amikacin & 37 & $48.68 \%$ \\
\hline gentamicin & 58 & $76.31 \%$ \\
\hline imipenem & 33 & $43.42 \%$ \\
\hline meropenem & 22 & $28.94 \%$ \\
\hline Piperacillin -tazobactam & 38 & $50 \%$ \\
\hline
\end{tabular}

Table.5 Antibiotic susceptibility testing of Acinetobacter baumannii $(\mathrm{n}=42)$

\begin{tabular}{|l|c|c|}
\hline Antibiotics & Resistance & percentage \\
\hline ceftazidime & 39 & 92.85 \\
\hline cefepime & 31 & $73.80 \%$ \\
\hline amikacin & 28 & $66.6 \%$ \\
\hline gentamicin & 39 & $92.85 \%$ \\
\hline imipenem & 16 & $38.10 \%$ \\
\hline meropenem & 11 & $26.19 \%$ \\
\hline Piperacillin -tazobactam & 18 & $42.85 \%$ \\
\hline
\end{tabular}

Table.6 Carbapenem resistance in nonfermenting gram negative bacilli 


\begin{tabular}{|l|l|l|}
\hline Total no. of isolates 118 & $\begin{array}{l}\text { Imipenem } \\
\text { resistance }\end{array}$ & $\begin{array}{l}\text { Meropenem } \\
\text { resistance }\end{array}$ \\
\hline Pseudomonas aeruginosa (76) & $33(43.42 \%)$ & $22(26.94 \%)$ \\
\hline Acinetobacter baumannii (42) & $16(38.10 \%)$ & $11(26.19 \%)$ \\
\hline Total (118) & $49(41.52 \%)$ & $33(27.96 \%)$ \\
\hline
\end{tabular}

Non-Fermenting Gram Negative Bacilli (NFGNB); world-wide over the years with varying frequencies of Pseudomonas aeruginosa and Acinetobacter baumannii in particular are most often associated with Carbapenem resistance causing fatal lower respiratory tract infections in patient admitted in ICUs.In our study,306 (74.16\%) among 430 were showing growth of pathogenic isolates. This is consistent with study conducted by Isa H. et al., (Isa H., Mahmood and Tirmidhi2010) showing high prevalence rate of isolation i.e. (92.5\%), and contradict with study conducted byMishra et al., and V.

Ramana et al., (Mishra et al., 2012; V. Ramana et al., 2013) showing isolation rate of $44 \%$ and $39.4 \%$ respectively. Higher isolation rate is may be due to proper sample collection with timely transportation and before starting antibiotics. In this study gram negative isolates $227(74.18 \%$ ) were more frequently isolated than gram positive isolates $79(25.82 \%)$. Other study conducted by Regha et al., (Regha et al., 2018) Galatelatabaswanna et al., (Galatelatabaswanna et al., 2015) and Ravichitra et al., (Ravichitra et al., 2016) also showing higher isolation of gram negative than gram positive bacteria. Gram negative prevalence is may be due to unequal cases of community acquired infections and hospital acquired infections.

In our study, among total 227 isolated gramnegative bacteria, 118 were nonfermenting gram negative bacilli. Among 118 nonfermenting gram negative bacilli 76 were Pseudomonas aeruginosa and 42 were Acinetobacter baumannii. These nonfermenting gram negative isolates were tested for antibiotic susceptibility for carbapenems and other antibiotics. Our study shows higher carbapenem resistance in Pseudomonas aeruginosa than Acinetobacter baumannii. This is consistent with study conducted by Devi p et al., (Devi p et al., 2015) and contradict with Taneja $\mathrm{N}$ et al., and Agrawal S et al., (Taneja $\mathrm{N}$ et al., 2003; Agrawal S et al., 2017) where carbapenem resistance was found more frequently in Acinetobacterbaumannii than Pseudomonas aeruginosa. In our study imipenem resistance to Pseudomonas aeruginosa and Acinetobacter baumannii is found to be $43.42 \%$ and $38.10 \%$ respectively. our study is consistent with study conducted by Devi p et al., (Devi p et al., 2015) showing 42\% and $28 \%$ imipenem resistance to Pseudomonas aeruginosa and Acinetobacter baumannii respectively.

Our study is contradicting with study conducted by Agrawal S et al., (Agrawal S et al., 2017) showing imipenem resistance to Pseudomonas aeruginosa and Acinetobacter baumannii $52 \%$ and $90.54 \%$ respectively. This may be due to Frequent use of imipenem might attribute to resistant against imipenem of its multidrug-resistant pattern and its ability to adapt to various environments (Jean SS et al., 2014.).

In our study meropenem resistance to Pseudomonas aeruginosa and Acinetobacter baumannii is found to be $28.94 \%$ and $26.19 \%$ respectively. Our study is consistent with study conducted by Hashem $\mathrm{H}$. et al., (Hashem H. et al., 2016) showing 24\% of 
meropenem resistance in Pseudomonas aeruginosa and Sharma D. et al., (Sharma D. et al., 2015) and Cai B. et al., (Cai B. et al., 2017) showing $19 \%$ and $26 \%$ of meropenem resistance to Acinetobacter baumannii respectively. study conducted by Sahu et al., (Sahu et al., 2016) showing higher resistance of meropenem in Pseudomonas aeruginosa $(84 \%)$ and in Acinetobacter baumannii $(81.9 \%)$.

The relatively low prevalence in our study is no way a reason for satisfaction, since our study was done in a setup including rural population, in whom carbapenem often are not the first-choice drug. Matter of concern is selective multiplication and dissemination of multiple resistant NFGNB in near future.

Our study has put forward the carbapenem resistance NFGNB among the respiratory isolates of our ICUs. In view of carbapenem resistance amongst the isolates, antibiotic therapy should be advocated or modified following culture and sensitivity. This would not only help in the proper treatment of the patient but also would discourage the indiscriminate use of available antibiotics and stop the spread of drug resistance bacteria. Moreover, considering the prevalence of carbapenem resistant bacteria, it is necessary to carry out regular monitoring of drug resistance and molecular characteristics of carbapenem resistant isolates in this region.

\section{References}

Agarwal Sonika, Barnali Kakati, Sushant Khanduri, and Shalini Gupta. 2017. "Emergence of Carbapenem Resistant Non-Fermenting Gram-Negative Bacilli Isolated in an ICU of a Tertiary Care Hospital." Journal of Clinical and Diagnostic Research 11(1): DC04-7.

Brahmadathan KN, P Gladstone, and Priya Rajendran. 2005. "Incidence of
Carbapenem Resistant Nonfermenting Gram Negative Bacilli from Patients with Respiratory Infections in the Intensive Care Units." Indian Journal of Medical Microbiology 23(3): 189.

Cai, Bin et al., 2017. "Prevalence of Carbapenem-Resistant Gram-Negative Infections in the United States Predominated by Acinetobacter baumannii and Pseudomonas Aeruginosa." Open Forum Infectious Diseases 4(3). http://academic.oup.com/ofid/article/doi /10.1093/ofid/ofx176/4082904/Prevalen ce-of-CarbapenemResistant GramNegative (December 21, 2019).

Clinical and Laboratory Standards Institute. Performance Standards, antimicrobial susceptibility testing; Twenty-nineth informational supplement. CLSI, and document M100 - Clinical and Laboratory standards Institute Wayne 2019.

Devi, P., P. Reddy, and Maria John. 2015. "Incidence of Carbapenem Resistant Nonfermenting Gram Negative Bacilli from Patients with Respiratory Tract Infections among Intensive Care Units." International Journal of Research in Medical Sciences 3(6): 1368-71.

Duguid J.P. 1996 "Staining methods." Editors: J.G. Collee, A.G. Fraser,B.P. Marmion, A.Simmons. In Mackie \& McCartney Practical Medical Microbiology, 14nth Edition. Churchill Livinstone Elsevier,.p793-812.

Galate Lata Baswanna \& Gajbhiye, Pradnya Shankarrao. 2015. "Microbiological Profile and Antibiogram Pattern of Lower Respiratory Tract Infection." BEST International Journal of Humanities, Arts, Medicine and Sciences (BEST: IJHAMS) 3(4): 1-6.

Gales A. C. et al., 2001. "Emerging Importance of Multidrug- Resistant Acinetobacter Species and 
Stenotrophomonas Maltophilia as Pathogens in Seriously Ill Patients: Geographic Patterns, Epidemiological Features, and Trends in the SENTRY Antimicrobial Surveillance Program (1997-1999." Clinical Infectious Diseases 32(s2): S104-13.

Gonlugur Ugur, Mustafa Zahir Bakici, Ibrahim Akkurt, and Tanseli Efeoglu. 2004. "Antibiotic Susceptibility Patterns among Respiratory Isolates of GramNegative Bacilli in a Turkish University Hospital." BMC Microbiology 5: 1-5.

Goossens, Herman. 2003. "Susceptibility of Multi-Drug-Resistant Pseudomonas Aeruginosa in Intensive Care Units: Results from the European MYSTIC Study Group." Clinical Microbiology and Infection 9(9): 980-83.

Hashem Hany et al., 2016. "Carbapenem Susceptibility and Multidrug-Resistance in Pseudomonas Aeruginosa Isolates in Egypt." Jundishapur Journal of Microbiology 9(11).

Isa, H, A Mohammed, and A B Tirmidhi. 2010. "Antimicrobial Susceptibility of Some Respiratory Tract Pathogens to Commonly Used Antibiotics at the Specialist Hospital , Yola , Adamawa State , Nigeria." Journal of Clinical Medicine and Research 2(August): 13542.

http://www.academicjournals.org/JCM R (December 11, 2019).

J.G.Collee,J.P.Duguid,A.G.Fraser,B.P.marmi on, A.Simmons. 1996. " Laboratory diagnosis in infective syndromes." Editor J.G. Collee, A.G.Fraser, B.P. marmion, A.Simmons. In Mackie \& McCartney Practical Medical Microbiology, 14nth edition. Churchill Livinstone Elsevier, NEW YORK,p. 63. J.G.Collee,J.P.Duguid,A.G.Fraser,

B.P.marmion A.Simmons. " Laboratory diagnosis in infective syndromes." Editor J.G. Collee, A.G.Fraser,
B.P.marmion, A.Simmons. In Mackie \& McCartney Practical Medical Microbiology, 14nth Edition. Churchill Livinstone Elsevier, New York p.6466.

J.G.Collee,R.S.Miles,B.Watt.1996. "Tests for identification of bacteria." Editor J.G.Collee,A.G.Fraser,B.P.marmion, A.Simmons.In Mackie \& McCartney Practical Medical Microbiology, 14nth edition. Churchill livinstone Elsevier, new york p.131-149.

Jean, S. S. et al., 2014. "Elizabethkingia Meningoseptica: An Important Emerging Pathogen Causing Healthcare-Associated Infections." Journal of Hospital Infection 86(4): 244-49.

Livermore, David M. 1992. "Interplay of Impermeability and Chromosomal $\beta$ Lactamase Activity in ImipenemResistant Pseudomonas Aeruginosa." Antimicrobial Agents and Chemotherapy 36(9): 2046-48.

Mishra, SK et al., 2012. "Recent Trend of Bacterial Aetiology of Lower Respiratory Tract Infection in a Tertiary Care Centre of Nepal." International Journal of Infection and Microbiology 1(1): 3-8.

Mukhopadhyay, Chiranjoy, Anudita Bhargava, and Archana Ayyagari. 2003. "(PDF) Role of Mechanical Ventilation \& Development of Multidrug Resistant Organisms in Hospital Acquired Pneumonia." Indian Journal of Medical Research 118(DEC.): 229-35.

Quinn, John P. 1998. "Clinical Problems Posed by Multiresistant Nonfermenting Gram- Negative Pathogens." Clinical Infectious Diseases 27(s1): S117-24.

Ravichitra, K.N. N, and S. Subbarayudu. 2016. "A Study on the Etiological Trends and Antibiogram of Lower Respiratory Tract Infections (LRTIs) at a Tertiary Care Hospital.” International 
Journal of Current Microbiology and Applied Sciences 5(12): 18-22. http://dx.doi.org/10.20546/ijcmas.2016. 512.003 (December 6, 2019).

Regha I R, and Sulekha B. 2018. "Bacteriological Profile and Antibiotic Susceptibility Patterns of Lower Respiratory Tract Infections in a Tertiary Care Hospital, Central Kerala." IP International Journal of Medical Microbiology and Tropical Diseases 4(4): 186-90.

Sahu, Manoj Kumar et al., 2016. "Incidence , Microbiological Profile of Nosocomial Infections , and Their Antibiotic Resistance Patterns in a High Volume Cardiac Surgical Intensive Care Unit." C: 281-87.

Sharma D,Vyas N,Sinha P,Mathur A.,2014."Non fermentative gram negative bacilli as nosocomial pathogens: Identification and antibiotic sensitivity in clinical samples of indoor patients."Nepal Journal of Medical
Sciences,03(2);101-105.

Taneja N, Aharwal S m., Sharma M. 2003. "Imipenem resistance in nonfermentors causing nosocomial urinary tract infections." Indian J Med Sci.;57:294-9.

Tognim MC, Andrade SS, Silbert S, Gales AC, Jones RN, Sader HS. 2004."Resistance trends of Acinetobacter spp.in Latin America and characterization of international dissemination of multi-drug resistant strains: five-year report of the SENTRY Antimicrobial Surveillance Program." Int J Infect Dis.; 8:284-9

V RamanaK, Anand Kalaskar, Mohan Rao, and Sanjeev D Rao. 2013. "Aetiology and Antimicrobial Susceptibility Patterns of Lower Respiratory Tract Infections (LRTI) in a Rural Tertiary Care Teaching Hospital in Karimnagar, South India." American Journal of Infectious Diseases and Microbiology 1(5): 101-5.

\section{How to cite this article:}

Seematai Prakash katole and Nilekar Sandeep Laxmikant. 2020. Prevalence of Carbapenem Resistance in Nonfermenting Gram Negative Bacteria in Patients with Respiratory Tract Infection Admitted in Intensive Care Units in Tertiary Care Centre. Int.J.Curr.Microbiol.App.Sci. 9(02): 1363-1371. doi: https://doi.org/10.20546/ijcmas.2020.902.159 